\title{
Opportunities for Volunteered Geographic Information Use in Spatial Planning
}

\author{
Matej Nikšič $\check{c}^{\star}$, Michele Campagna ${ }^{\dagger}$, Pierangelo Massa ${ }^{\dagger}$, \\ Matteo Caglioni ${ }^{\ddagger}$, Thomas Theis Nielsen ${ }^{\S}$ \\ *Urban Planning Institute of the Republic of Slovenia, Ljubljana, Slovenia, \\ matej.niksic@uirs.si \\ ${ }^{\dagger}$ DICAAR, Università di Cagliari, Cagliari, Italy \\ ¥Université Côte d’Azur, CNRS, ESPACE, France \\ ${ }^{\S}$ University of Roskilde, Roskilde, Denmark
}

\begin{abstract}
This chapter highlights two types of georeferenced User-Generated Content (geo-UGC) that show considerable potential for fruitful usage in spatial planning in practice: Volunteered Geographic Information (VGI) and Social Media Geographic Information (SMGI). By describing selected case studies, the chapter illustrates how geo-UGC can be used at different stages of spatial planning processes, supporting a more pluralist understanding of places, fostering the collaboration between decision-makers and contributing to a more participatory practice in spatial planning. The Geodesign approach is used as the framework for underpinning the discussion. Selected case studies developed by the authors are presented showing how geo-UGC can be beneficial for building knowledge on current urban and territorial dynamics, for identifying possible alternative futures and for finding agreement on preferable future developments. In all the selected cases, large numbers of users were involved
\end{abstract}

How to cite this book chapter:

Nikšič, M, Campagna, M, Massa, P, Caglioni, M, Nielsen, T T. 2017. Opportunities for Volunteered Geographic Information Use in Spatial Planning. In: Foody, G, See, L, Fritz, S, Mooney, P, Olteanu-Raimond, A-M, Fonte, C C and Antoniou, V. (eds.) Mapping and the Citizen Sensor. Pp. 327-349. London: Ubiquity Press. DOI: https://doi.org/10.5334/bbf.n. License: CC-BY 4.0 
in collecting volunteered content. The findings are also interpreted within the Smart Cities paradigm, where participation is an essential factor for building successful smart communities.

\section{Keywords}

VGI, SMGI, urban planning, urban design, Geodesign, Smart Cities

\section{Introduction}

Spatial planning, as an interdisciplinary practice of managing the development of space in its physical, functional and socio-economic dimensions, aims to provide efficient, economically viable, just and sustainable space arrangements. It is traditionally a competence of a state, regional or local authority, and usually involves a number of actors and institutions.

In the last few decades a stronger emphasis has been placed on the involvement of the community and the users of space in urban planning procedures. In part this has arisen from the general democratisation of the processes in contemporary societies in many Western countries, but it has also emerged out of a need to avoid conflicts between opposing parties, which often have contrary interests in space (Arnstein, 1969; European Commission, 2003; McTague and Jakubowski, 2013; Cerar, 2014).

Prior to the widespread diffusion of new Information and Communication Technologies (ICT), public participation was largely understood as a form of public commenting on already prepared plans, while emerging technologies have opened up new and innovative ways of realising the active involvement of the wider public in spatial planning (Bizjak, 2012). Opportunities have arisen in different fields, e.g. improving the communication between authorities and citizens, providing more accurate and up-to-date databases on the current state of territorial conditions, and collecting the ideas and visons for future developments of different stakeholders (Berntzen et al., 2005; Brabham, 2009; Seltzer and Mahmoudi, 2013).

As a dynamic and complex socio-technical process, spatial planning may entail multi-faceted paradigms originating in a variety of workflows in practice. The aim of this chapter is to use the concept of Geodesign (Steinitz, 2012), which is one of many possible ways of approaching spatial planning, to explore the opportunities for exploiting georeferenced User-Generated Content (geoUGC) in spatial planning. We can differentiate between two main categories of geo-UGC of particular interest in spatial planning, either as an information resource or as a communication platform, or both: Volunteered Geographic Information (VGI), which is geo-UGC purposely collected by a group of users for a given purpose (e.g. OpenStreetMap.com); and Social Media Geographic 
Information (SMGI), which is geo-UGC collected passively (e.g. Twitter.com; instagram.com) or actively (e.g. fixmystreet.org; projectnoah.org; carticipe.net) on social networking platforms. In the next section, the Geodesign approach is outlined, along with the opportunities for effective use of geo-UGC. This is followed by a set of case studies from the authors, which illustrate how geoUGC has been used in planning, relating these examples to different stages in the Geodesign approach. Finally, we consider how VGI and SMGI can support 'smart cities' initiatives.

\section{The Geodesign Approach: Opportunities Arising from VGI and SMGI}

In the last decade, the term Geodesign has gained popularity among a growing number of spatial planners, landscape architects and Geographic Information Systems (GIS) scholars, formalising an innovative approach to planning and design deeply rooted in geographic analysis and at the same time able to foster collaboration in decision-making. Geodesign may be defined as an integrated process, informed by environmental sustainability appraisal, that aims to address complex problems related to territorial and environmental issues and to social and economic matters (Dangermond, 2010). The main novelty in the Geodesign approach is the extensive use of digital spatial data and processing and of communication resources such as ICT and GIS, aimed at easing the integration of societal and scientific knowledge in planning, design and decision-making (Ervin, 2011). Current technologies may be considered mature enough to exploit ICT support in spatial planning processes, overturning the barriers that in the past limited the use of new technologies in practice (Göçmen and Ventura, 2010). Additionally, ICT, the Internet and, more recently, Web 2.0 technologies are increasingly channeling digital Geographic Information (GI) into the daily lives of a growing number of users. This phenomenon is leading to a paradigmatic shift in the contents and characteristics of GI, as well as in its modes of production and dissemination (Elwood et al., 2012). In the spatial planning domain, this unprecedented wealth of digital GI provides great opportunities for advances in methodologies such as Geodesign, fostering opportunities for supporting design, analysis and decisionmaking processes. Most of the opportunities arising for innovation emerge from the avalanche of spatial big data, which Web 2.0 technologies are making available to the wider public.

In the last two decades, developments in Spatial Data Infrastructures (SDIs) have enabled access to digital GI produced and maintained by public or private institutions for public or business purposes. In Europe, the implementation of Directive 2007/02/CE, establishing a shared Infrastructure for Spatial Information in Europe (INSPIRE), fostered the development of National and Regional SDIs in the Member States, allowing the public access and reuse of available 
official information, or Authoritative Geographic Information (A-GI), according to common data, technology and policy standards. Secondly, several platforms, continuously flourishing through the Internet as a result of Web 2.0 technologies, are supporting the production and diffusion of User-Generated Content (UGC), which often has a geographic reference embedded, potentially transforming the Web into a big warehouse of spatial data (Elwood et al., 2012). Spatial UGC is commonly labelled as VGI, emphasising the voluntary activities of users to collect and contribute information related to the geographic world (Goodchild, 2007). In spatial planning, VGI may supply both experiential knowledge from local communities and expert knowledge from professionals in a bottom-up approach, e.g. through citizen science initiatives. SMGI, which is a subset of UGC (Campagna, 2014), is spatial information produced and shared through social network sites, and may allow for the collection of quantitative GI related to a study area but also of qualitative information concerning the perceptions of users about phenomena in space and time. Indeed, SMGI is different from traditional common vector spatial datasets such as A-GI supplied by institutional SDIs, which exclusively feature spatial and thematic information: the SMGI data model features spatial, temporal and multimedia dimensions (i.e. image, text, video and audio), as well as a user dimension, including specific information about the user profiles. Furthermore, in certain cases, the SMGI data model also includes a preference dimension, i.e. SMGI appreciation expressed by the social network community by means of scores, stars or likes/dislikes, thus widely expanding the range of analytical opportunities for planners and analysts (Campagna et al., 2015). A comparison between the SMGI and traditional A-GI data models is shown in Figure 1.

The general SMGI data model may foster advances in spatial planning methodologies and may be a valuable complement to traditional A-GI that can support several stages of the Geodesign process. To formalise the Geodesign approach, Steinitz (2012) proposed a methodological framework that relies on six models: representation, process, evaluation, change, impact and decision models. These are iteratively implemented to design future development

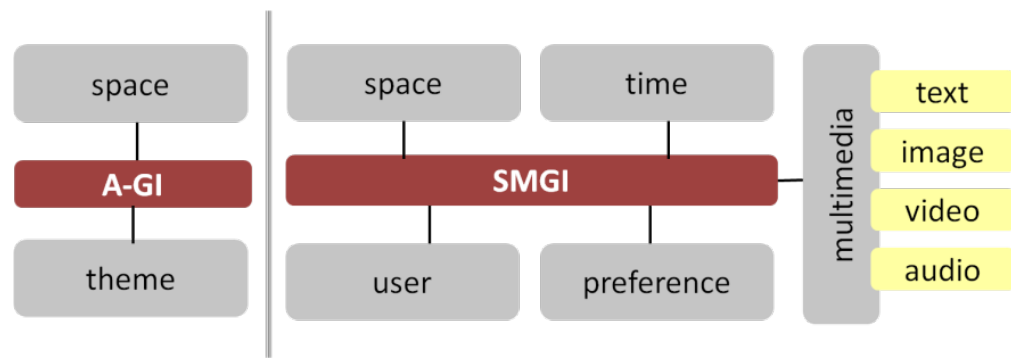

Fig. 1: Comparison between the A-GI data model and the SMGI data model (Adapted from Campagna, 2016). 
alternatives and to identify their potential consequences by means of a territorial context description, an analysis of the dynamics and an evaluation of the impacts. The first three models describe the present situation of the territorial context considering (1) the environmental system, and (2) explaining its evolution, mainly focusing on (3) opportunities and threats that may arise from the current situation. Conversely, the last three models define potential alternatives for (4) transforming the system, (5) assessing the transformation alternatives' potential beneficial or dangerous impacts on environmental and human systems, and eventually (6) supporting stakeholders during the decision-making process.

VGI and SMGI may thus be used to complement the availability of official information for the implementation of all the Geodesign models, supplying useful societal data. In the representation model, SMGI may be used to facilitate the description of a geographic context, providing experiential knowledge that is usually dismissed in official information and integrating A-GI with a pluralist vision of geographic phenomena, which may be used to identify social and cultural dynamics affecting the area. For example, SMGI from several Location-Based Social Networks (LBSNs) has been used to identify the most appreciated Points of Interest (POIs) and landmarks in a study area (Jankowski et al., 2010), the pedestrian paths in the historical centre of a city, the neighbourhoods featuring the lowest number of services and the different land uses in an urban environment (Frias-Martinez et al., 2012), and to classify urban areas (Noulas et al., 2011).

Regarding the development of process models, SMGI may be used to investigate how detected phenomena evolve over time thanks to the real-time supply of information, which may be used for monitoring and to feed predictive models for studying future trends and dynamics. SMGI may also be extracted and analysed for different periods from different social networks, investigating first whether current phenomena were already present in the past and secondly if the potential factors affecting these phenomena persist, in order to evaluate the future situation. Similarly, users' preferences about urban mobility or cultural dynamics may be elicited from SMGI with the aim of feeding agent-based models that can simulate individual behaviours.

In the evaluation model, SMGI may be used to assess the current situation of the geographic area, due to the preferences, opinions and behaviours of users, which are embedded in this source of information. For instance, SMGI may be extracted for studying the movements of users in urban environments (Jankowski et al., 2010), the utilisation rates of public spaces (Torres and Costa, 2014) and the neighbourhood perceptions of users (Massa and Campagna, 2014), as well as the dynamics of different population groups (Longley et al., 2015).

Furthermore, social networks, representing a means to gain useful insights about the social and cultural dynamics of an area, may support the development of alternative scenarios in the Geodesign change model, and, at the same time, they may be used to actively involve local communities during planning 
and design (Eräranta et al., 2015). In addition, SMGI may be useful in the Geodesign impact model to assess the potential alternative effects on the territory, due to the possibility to present change scenarios to the local community and to collect feedback using a participatory planning approach (Rantanen and Kahila, 2009).

Finally, despite the difficulties in transposing the experiential knowledge of local communities into practice (Nonaka and Takeuchi, 1995), SMGI might be used to foster a communicative process among participants in the decision model, wherein the mutual integration of expert and experiential knowledge is a crucial step (Khakee et al., 2000) to build a shared, sustainable and democratic development process for the territory. Commonly, a local community's experiential knowledge is considered exclusively an opinion in planning processes (Fischer, 2000); however, the technical knowledge of experts may not be sufficient to properly guide decision-making processes (Lindblom, 1990). Hence, the integration of A-GI and SMGI may support the decision model, and may foster the development of more transparent, pluralist and democratic decision-making.

In the next section, selected case studies that we carried out will be briefly outlined to demonstrate the value of SMGI at different stages of the planning process, using the Geodesign framework as a reference.

\section{Case Studies on the Value of VGI and SMGI in Spatial Planning and Design}

\subsection{Representation Model}

Representation of geographic information is extremely important for planners and citizens. Both of them use visualisation methods to explore the real world and as a basis for analysing different scenarios based on spatial data. Visualisation is one of the possible representations for VGI, and probably the most powerful one. Geovisualisation explores geospatial information and supports decision-making processes in spatial planning.

One innovative example of representation is the interactive visualisation of OpenStreetMap (OSM), which allows users to upload quantitative and qualitative data in a Web-based GIS, as was the case in the GeoCampPACA event. GeoCampPACA2016 was a mapping party organised by OSM France, the Provence-Alpes-Côte d'Azur (PACA) French region and the region's centre for geoinformation, CRIGE (Figure 2). The aim of this event was to make a survey related to different modes of transport, such as pedestrian, bicycle, car, bus, tram and train routes, including infrastructure, equipment, services, etc., and to represent the information in cartographic form. This two-day event was a real participatory mapping operation, open to all students in geography and GIS of the PACA French region. The first day was dedicated to OSM protocols 


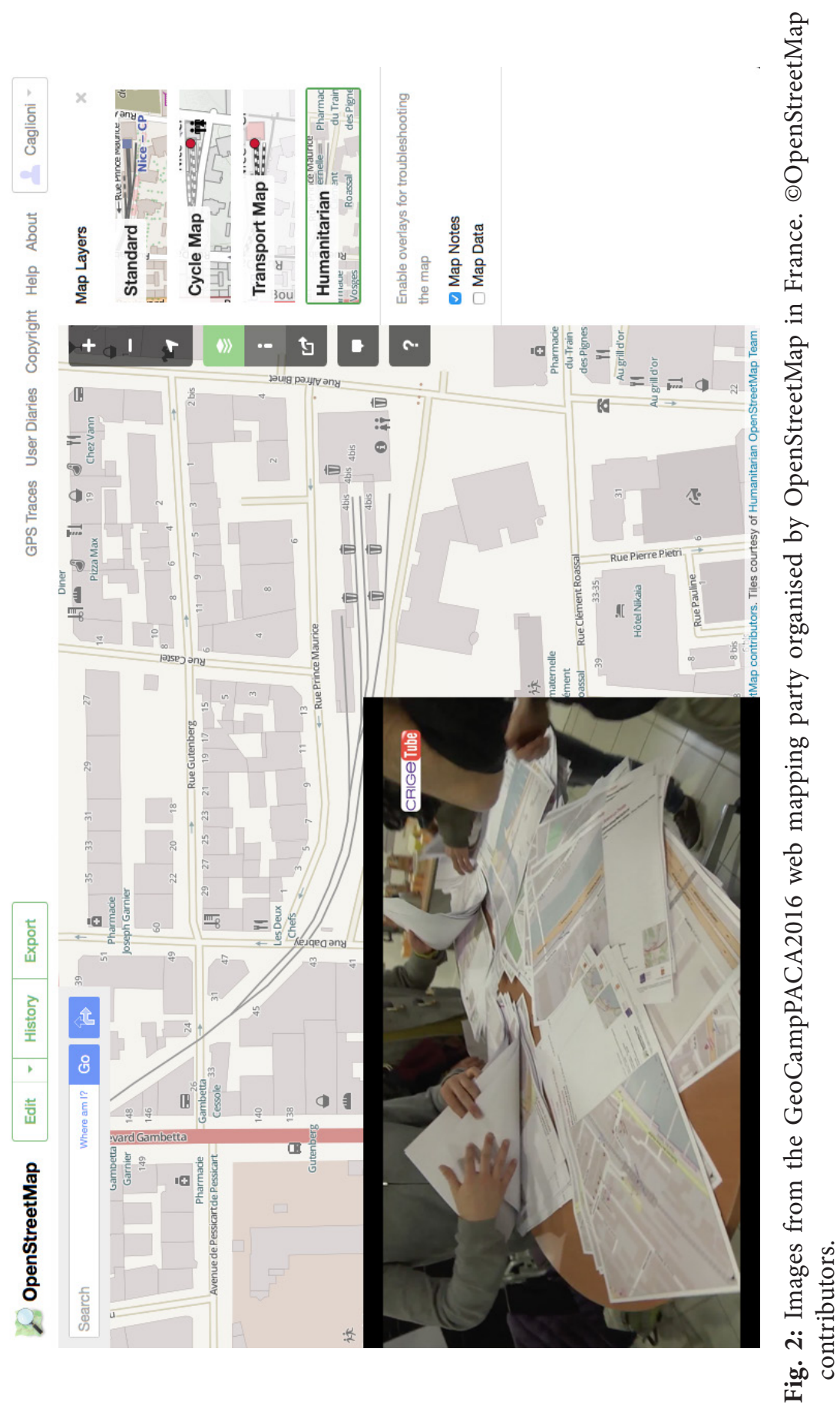


and basic notions of crowdsourcing and GIS, while the second day was devoted to practical and field activities in the different main train stations of the region. The event facilitated the creation of open data available on the OSM portal, while allowing participants to gain a better understanding of their surrounding environment.

\subsection{Process Model}

As mentioned earlier, the Geodesign process model concerns the understanding of current territorial dynamics. This model will be illustrated with two examples. The first is a case study of volunteered urban cycling information via GPS devices, which demonstrates how VGI can help planners monitor current behaviour and preferences in movement and transport dynamics. The second case study shows how the daily spatial practices of homeless people can be better comprehended through the use of VGI.

Rising motorisation rates in Europe and related environmental issues have created a demand for new urban planning and design paradigms in relation to urban transportation (Eurostat, 2012; Knoflacher, 2007; Zubelzu and Fernández, 2016). The new spatial planning paradigms are advocating for a change in the proportion of means of mobility in favour of non-motorised and public transportation to account for personal motorised traffic. Within these endeavors, urban cycling is gaining momentum, and new strategies have been developed to accommodate urban cycling into existing cities.

One of the related urban planning issues is the improvement of the existing and provision of new cycling infrastructures. Contemporary smart approaches, however, do not deal with the infrastructure as a physical element, but deal with it solely in relation to perceptual and behavioural patterns, i.e. how people tend to perceive and use it; the main aim is to provide infrastructure that will be efficient and safe and to encourage enough people to use it regularly. A wide range of approaches have been developed to help understand what kind of cycling infrastructure is preferred and demanded by users in contemporary cities, and VGI is playing an increasingly important role in these developments (Latham and Wood, 2015; Yeboah and Alvanides, 2015; Winters et al., 2016).

Such an attempt has been made with CyCity, a research programme by the Swedish governmental agency Vinnova, with the aim to improve the knowledge on urban cyclists' preferences in route choices (Envall and Koucky, 2013). Through a combined technique of using GPS devices and online questionnaires, each participating urban cycler has provided valuable information for the planning and (re)design of cycling path networks in the cities of implementation (Ljubljana in Slovenia and Linköping in Sweden). For a limited time, participants were given user-friendly GPS devices and asked to record every biking route they made in the city, as well as filling out a questionnaire 
regarding qualitative data on the cycling routes (Tominc et al., 2012). Even though the GPS technology proved to be not very precise and accurate (e.g. the mapped polylines overlapped with built blocks, etc.), the research revealed a big potential to fulfil the needs of urban planning (Figure 3), namely in the following aspects:

- The appropriate amount of mapped cycling tracks clearly indicates where in the city the cycling trips densify, as well as where they are non-existent. The densely cycled areas may be regarded as potential locations to place and develop programmes that appeal to cyclists, which may generate new urban activities, much longed for in urban regeneration processes.

- Areas that have no records of tracks at all should be observed in detail to determine the reasons why and the possible solutions for increasing cycling opportunities.

- The cross-interpretation of GPS tracks and qualitative data offers an exclusive insight into how different sections of the cycling network are perceived by users and what their preferences are when choosing their cycling routes.

Urban transportation, as one of the most dynamic and changeable features of urban settlements, is certainly a planning sector that can greatly benefit from the usage of VGI, where urban cycling is just one example. As the main mission of urban settlements is to provide settings for human interactions and exchanges, it is important to reveal people's perceptions, expectations and desires in various fields of urban life. In this respect, the CyCity initiative showed that VGI can provide a valuable source of direct information.

Another example of how VGI has been used to shed light on the spatial practice of local communities is one launched in 2014 in Denmark. In the city of Odense, a project was initiated whereby the homeless population in the city was invited to participate in monitoring their daily spatial practices using portable GPS technology. Homeless people and other vulnerable groups are underrepresented in the planning and political apparatus of the modern city, so the physical planning of the city is not influenced by these groups, despite the fact that group members are often very present in the city, and often with no place else to turn to than the streets.

Much of the research to date has investigated homelessness and homeless mobility in the city (e.g. Wolch et al., 1993; Cloke et al., 2008), as well as in the countryside (Cloke et al., 2003). The spatial practice of homeless people has also been the topic of numerous studies. Some studies have focused on homelessness among immigrant groups in Europe (e.g. Pezzoni, 2011) while others have focused on gender issues (e.g. Crystal, 1984) involved in homelessness. However, only very few studies, if any, can be identified that utilise contemporary location technology in relation to monitoring the spatial practice of homeless groups. 


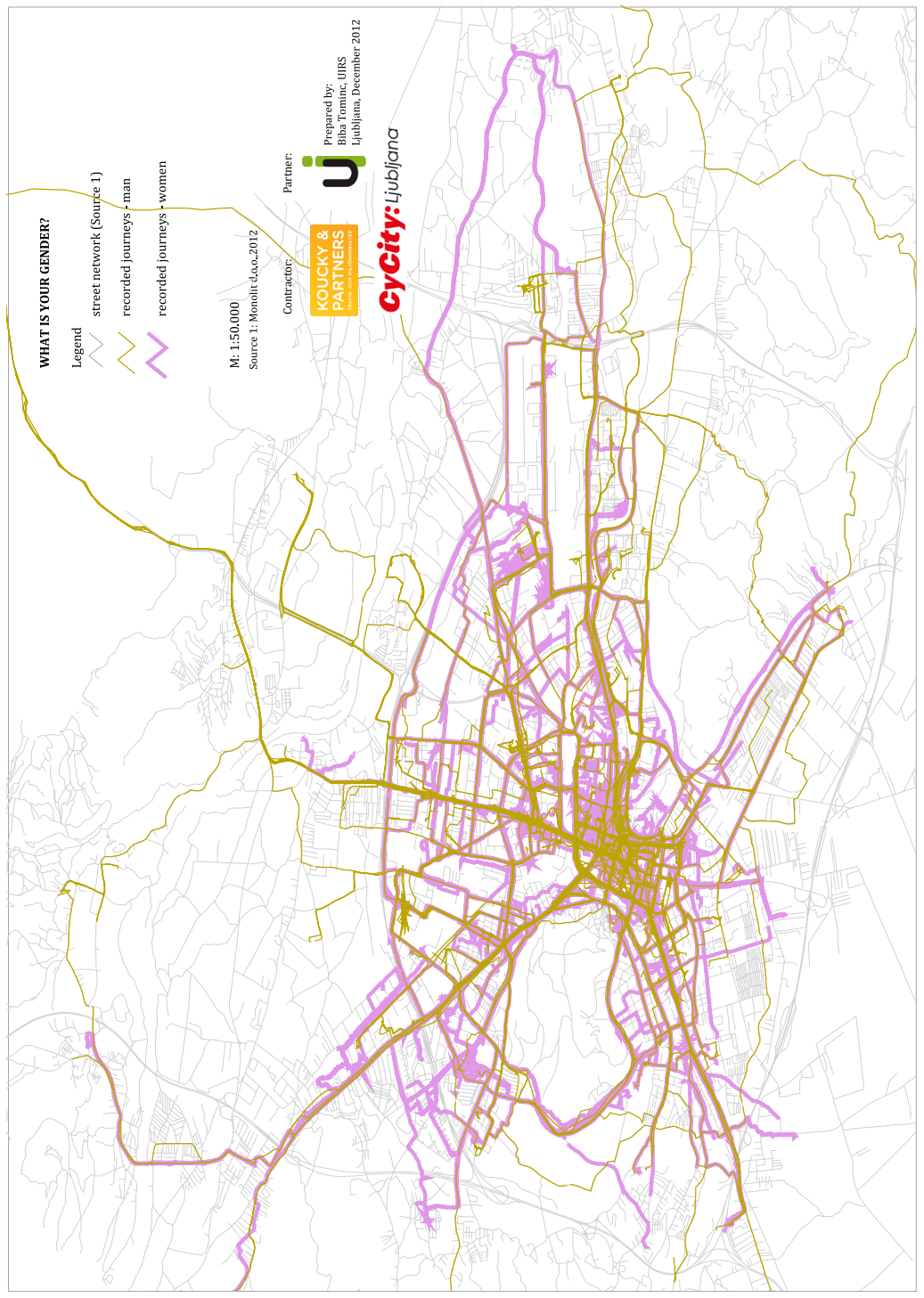

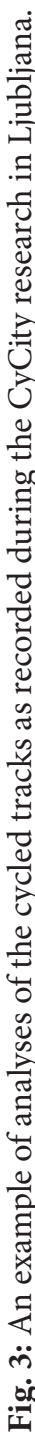


In the Odense project, data are collected twice a year. A number of GPS devices are left in one of the shelters operated by the Blue Cross NGO in collaboration with the municipality. The homeless people are encouraged to put a GPS device in their pockets and to hand the GPS back the next day. It is, to some extent, a leap of faith for the homeless to participate in such an enterprise, as many doubts and fears about the use of the data can be raised; here, the close collaboration with officials from the municipality and high ethical standards (F. Harvey, 2013) are paramount, as the data contributors have to be assured that data on their spatial patterns are not revealed to any third party. After one day of carrying, the GPS units are collected and the data are gathered and analysed.

To date, the project has implemented three data collection routines, and already the results are being used by officials in the municipality as part of the planning process. Data on mobility patterns have revealed new bottlenecks in the spatial practices of the homeless; confluences of mobility have been identified, and places for resting and meeting up have been confirmed or investigated as part of the data analysis. The results from these analyses and the new insights into homeless mobility are further being used in the physical planning of the city of Odense in order to identify places to erect new structures such as shelters and roofed open spaces for the homeless and other vulnerable groups. The results are also being considered whenever new projects are initiated in the city.

As such, the Odense project highlights the fact that locational data on vulnerable groups can be collected in a volunteered data collection regime and can be used very effectively as a means to give voice to a group of citizens that does not traditionally get heard in the physical planning of the city. This type of information, and empowerment, would not be possible without data being provided by contemporary techniques; users volunteering the data; and ethical procedures and analysis protocols to structure the understanding and use of the results in a manner that, on the one hand, meets the requirements of the planning organs of the municipality while, on the other hand, makes sense to the vulnerable groups volunteering the data.

\subsection{Evaluation Model}

Another example of the considerable value of VGI for urban planning is in the field of the (re)design and (re)establishment of the quality of open urban public spaces. Open public spaces are the most contested spaces of contemporary cities, as they are common spaces and different users and interest groups have different conceptions and aspirations related to them. At the same time they are the places that connect the urban population in real space and time and play a crucial role in the socio-economic dynamics of cities (Madanipour et al., 2014). 
In order to reveal people's spatial perceptions on urban public spaces, various techniques have been developed, from traditional mental mapping techniques inspired by Lynch (1960)'s work to a variety of contemporary IT-supported community techniques (Davis, 2007; Evans-Cowley, 2010; Bizjak, 2012).

The perceptual dimension of space, namely emotions related to concrete spatial arrangements, proves to be rather difficult to grasp in a form that could effectively support the processes of spatial planning; it is personally conditioned and varies greatly among individuals. Nevertheless, as technically supported VGI allows large samples to be collected, this aspect of urban planning may well find a way onto urban-planning agendas of the future, if the communication tools are adjusted to the knowledge and skills of the general public. A concrete example is the project outlined in Healey and Ramaswamy (2016), which explores possibilities to estimate and visualise sentiments through text mining methods, starting from short, incomplete text snippets on Twitter. Collections of real-time tweets are visualised in various ways: by sentiments, by topic, by location, by frequent terms and their co-occurrence, etc. Another very appropriate medium to reveal one's perception of space is photography and the descriptions attached to photographs. An example that has revealed the attitudes and perceptions of inhabitants regarding their immediate living environment through photography is the Human Cities (2016) online project (Figure 4). One of its many activities is a participatory collection of urban neighbourhood photographs. The project is based on a conviction that it is important to reveal the shared values that local inhabitants have to propose sensible urban design improvements to neighbourhoods. The Human Cities (2016) online photograph contest runs as a web-blog as well as a mobile phone app and has been organised with pre-defined thematic categories, e.g. Most pleasant place in my neighbourhood; Professions in my neighbourhood; My neighbour; Borders of my neighbourhood; Shared values in my neighbourhood. By analysing the photographs in each category and their subtitles, planners are given a deeper insight into the otherwise hidden layer of local environments, i.e. the interpretations of local places by users, which would not traditionally be taken into consideration in urban (re)design processes or would have to be undertaken through time-consuming interviewing.

\subsection{Change, Impact and Decision Models}

According to Simon (1969), any design process entails devising courses of action aimed at changing existing situations into preferred ones. In order to achieve a design, Simon (1969) proposes a three-tier iterative workflow of intelligence (i.e. the knowledge base is created), design (i.e. the alternative possible future courses of action are devised) and choice (where the preferable option is selected for implementation). These definitions and this approach can be considered applicable to the majority of spatial planning (and Geodesign) processes. 


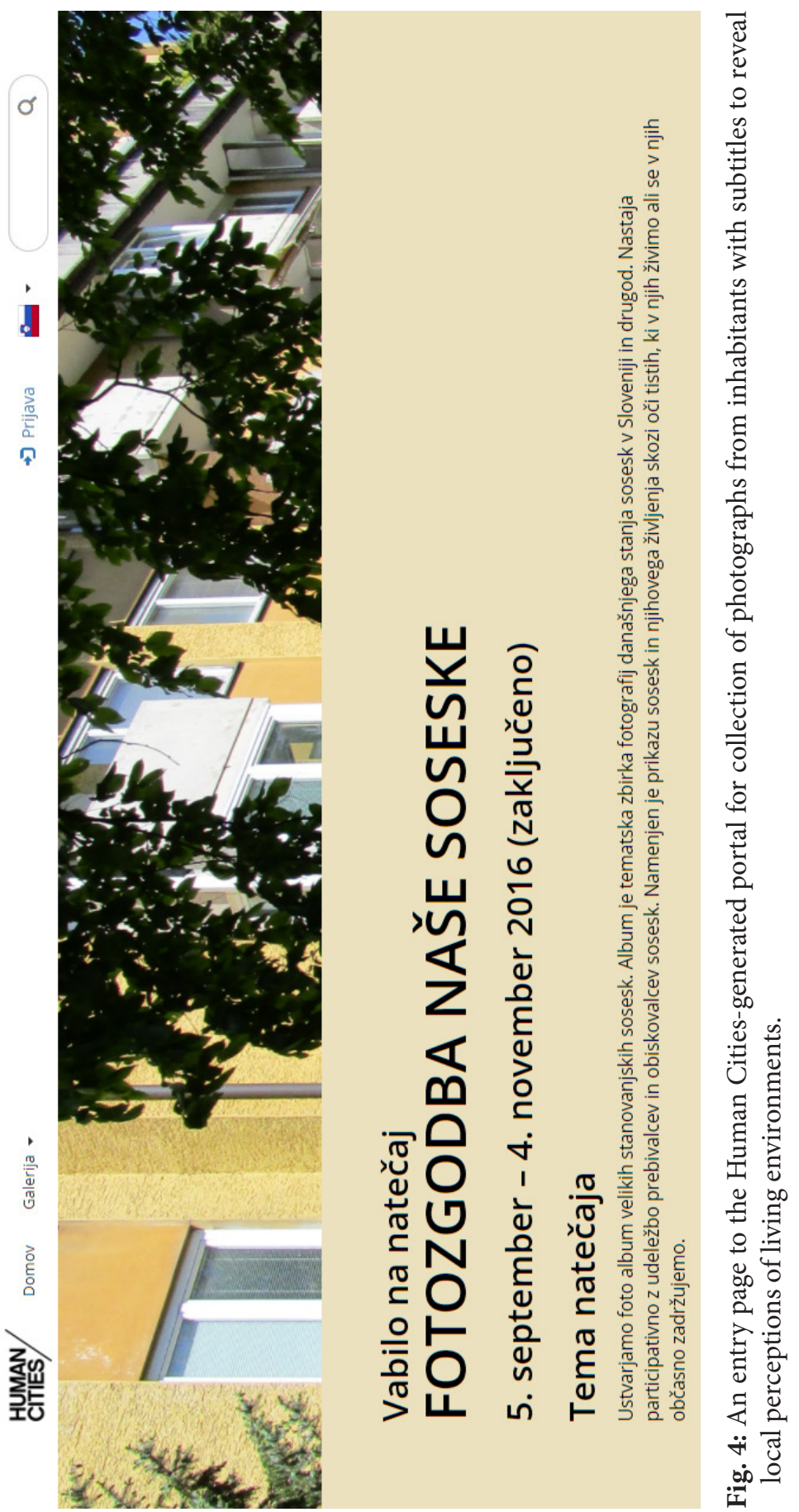


While previous case studies gave evidence of how VGI and SMGI can be used as information resources in the intelligence phase (i.e. the representation, process, and evaluation models in Geodesign), the following example shows how a Web-based collaborative platform with social networking features can be used to involve a large number of users in collecting volunteered content about design and choice (i.e. the change, impact and decision models in Geodesign).

While social media have been acknowledged as a potentially powerful means for engineering design and communication (Gopsill et al., 2013) and for supporting design studio work (Güler, 2015), until recently there have not been many Web-based platforms that were available to support collaborative planning and design. One example of such a platform is the geodesignhub. com platform developed by Ballal and Steinitz (2015), which implements the Steinitz Geodesign Framework (Steinitz, 2012). This platform, which has been successfully applied in a growing number of Geodesign workshops (Rivero et al., 2015; Nyerges et al., 2016; Campagna et al., 2016), allows for crowdsourcing of spatial data diagrams (i.e. georeferenced lines and polygons) representing design options (i.e. projects and policies) by a number of users (usually, but not necessarily, around 30). After the project and policy diagrams are collected (see Figure 5 for examples), the users can combine them in complex design syntheses that can be compared and evaluated against an impact model highlighting positive and negative impacts as well as costs (Figure 6). The platform also features a number of tools supporting negotiations so that the users participating in a workshop (which can be virtual and of same/different place/time types) can eventually find consensus on a common shared design.

The data stored in the project geodatabase of geoidesignhub.com can be considered as a design stemming from VGI. In addition, the data feature SMGI characteristics for design diagrams, i.e. they have spatial, temporal, user and preference dimensions, which can be further used to analyse the overall design process and participant behaviours. This demonstrates a novel approach in making value of crowdsourced design contents in spatial planning and (geo) design processes.

\section{VGI and SMGI to Support Smart Cities Initiatives}

The examples in the previous section aimed to support the idea that the increasing wealth of digital GI, made freely available through the Internet to analysts, planners and practitioners, may affect the current practices in spatial planning. While this process may still be at an early stage, it is likely that it may foster the development of 'smart city' strategies in the future. These strategies rely not only on the development of intelligent technologies but also on smart governance models according to which strategic and management decisions 


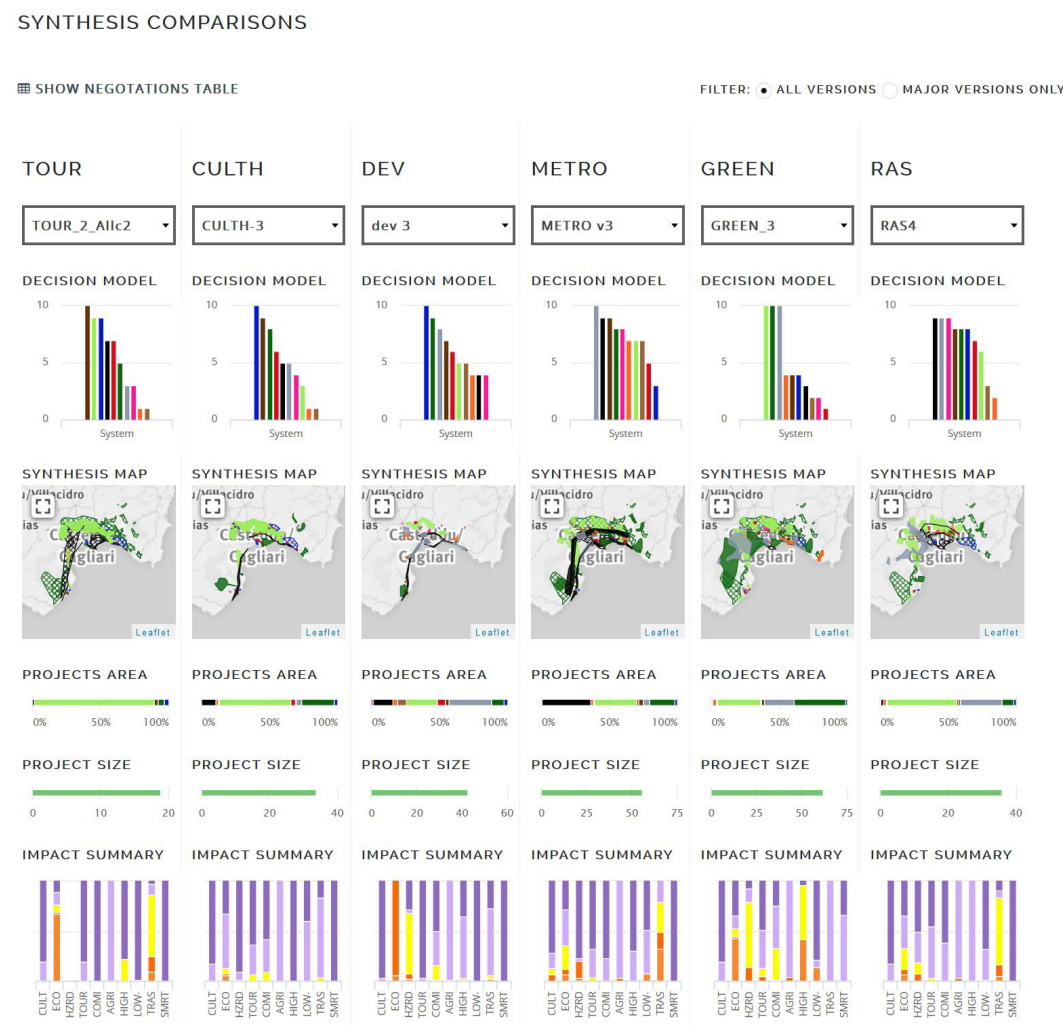

Fig. 5: Project and policy diagrams of the Cagliari (Italy) metro area crowdsourced at a Geodesign workshop in 2016 with geodesignhub.com. Each diagram in the matrix represents a project or a policy proposed by the participants during the crowdsourcing design exercise.

are informed by the real concerns and preferences of local communities as a result of real-time monitoring of needs, requirements and movements in urban environments.

In recent years, the label 'smart city' emerged as a broad term for identifying not only technology and smart infrastructure issues, but also strategies suitable to address societal problems generated by uncontrolled urbanisation and population growth in cities. Smart city strategies rely upon the Internet and Web 2.0 technologies to deal with several challenges, such as urban welfare, quality of life, societal participation and environmental sustainability (Schaffers et al., 2010). In the literature, many other smart city definitions may be found concerning different elements that contribute to the success of such initiatives. ICT represents the fundamental element to improve urban 


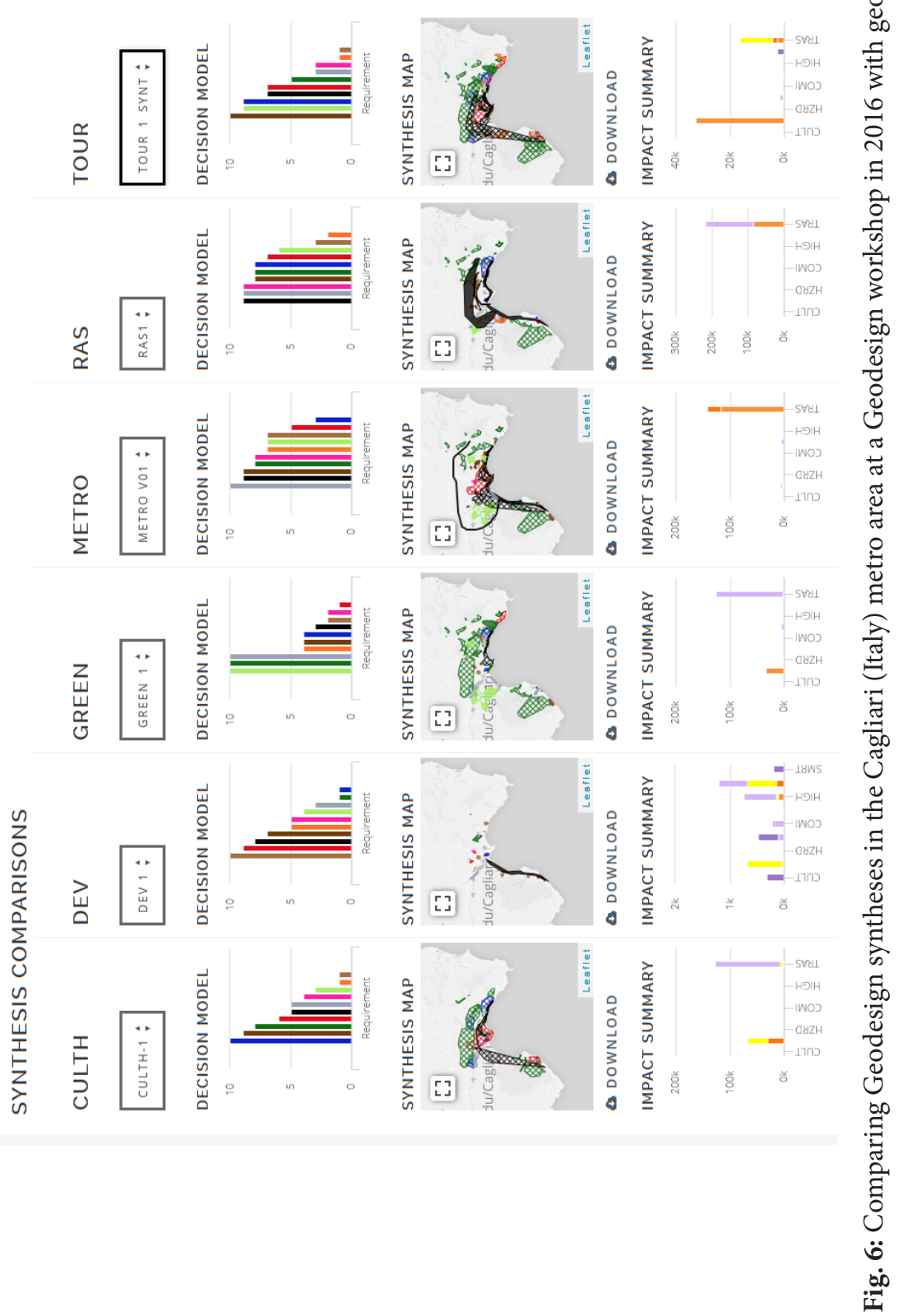


livability and sustainability, as well as to ensure the integration, efficiency and connections in the network of urban infrastructure and services (Washburn and Sindhu, 2009). However, technology is also intended to foster the spatial enablement of citizens by improving the access to, and the sharing and integration of, spatial data within urban services (Roche et al., 2012).

Nevertheless, the technological advances offered by ICT are not the only key elements leading to the success of smart city strategies, which also depends on the managerial, political and contextual dimensions of a city (Nam and Pardo, 2011). Several factors of the political dimension, such as governance, policy and local community, may play a central role in the development of such strategies. Indeed, many stakeholders are involved in the implementation of smart city strategies, and tight relationships between these actors are fundamental to ensure the exchange of knowledge in order to avoid the failure of projects (Scholl et al., 2009). At the same time, local communities play a fundamental role in defining smart city strategies by taking into account their own needs and opinions in order to guarantee transparency, democracy and pluralism while avoiding negative effects on their quality of life.

In light of the above considerations, the participation of local actors and people should represent an essential factor for tailoring successful smart city initiatives. In this regard, the unprecedented wealth of digital GI, namely SMGI and VGI, supplies insights not only about opinions, needs, perceptions and movements of local communities in the urban environment but also about design requirements and strategies, and may result in unprecedented opportunities for leading the development of smart city strategies, taking into account the real requirements of multiple stakeholders and of the local community and the people living in a place.

\section{Conclusions}

To conclude, let us remind ourselves of the concept of the Right to the city, addressed by D. Harvey (2008: 23) as follows: 'The right to the city is far more than the individual liberty to access urban resources: it is a right to change ourselves by changing the city. It is, moreover, a common rather than an individual right since this transformation inevitably depends upon the exercise of a collective power to reshape the processes of urbanisation. The freedom to make and remake our cities and ourselves is, I want to argue, one of the most precious yet most neglected of our human rights'.

As shown in this chapter, it is realistic to foresee broader and pluralist knowledge of the places enclosed in VGI and SMGI in the near future. This knowledge might be proficiently used by developing advanced technological solutions that integrate official and experiential information with an urban sensor data infrastructure, fostering the implementation of strategies informed and supported by local communities in a bottom-up approach. 
Such an approach must not be seen as beneficial only for citizens, but also equally for the authorities at different levels, and in particular for the decisionmakers who may one day rely upon VGI and SMGI to discriminate among different alternatives, paying specific attention to the concerns of users and selecting among the solutions that will satisfy the requirements of involved stakeholders. VGI and SMGI may also foster scenarios where city planners are able to listen to the local community's concerns and preferences, eventually interacting with the community through new technologies and communication channels to design alternative projects and to assess future development options through a constructive and participatory dialogue. This may sound rather like a distant promise, but it represents a possible future development in spatial and urban planning and design, thus contributing to finally making the concept of the right to the city a realised one.

\section{Reference list}

Arnstein, S.R., 1969. A ladder of citizen participation. Journal of the American Institute of Planners 35, 216-224.

Ballal, H., Steinitz, C., 2015. A Workshop in Digital GeoDesign Synthesis, in: Buhmann, E., Ervin, S., Pietsch, M. (Eds.), Proceedings of Digital Landscape Architecture 2015. Herbert Wichmann Verlag, Berlin, Germany, pp. 400-407.

Berntzen, L., Steinmann, R., Krek, A., 2005. Innovative use of Geographic Information Systems to facilitate collaboration between the government and citizens, in: Cunningham, P., Cunningham, M. (Eds.), Innovation and the Knowledge Economy: Issues, Applications, Case Studies. IOS Press, Amsterdam, Netherlands, pp. 746-753.

Bizjak, I., 2012. Improving public participation in spatial planning with Web 2.0 tools. Urbani izziv 112-124. DOI: https://doi.org/10.5379/urbani-izziven-2012-23-01-004

Brabham, D.C., 2009. Crowdsourcing the public participation process for planning projects. Planning Theory 8, 242-262. DOI: https://doi. org/10.1177/1473095209104824

Campagna, M., 2016. Social Media Geographic Information: Why social is special when it goes spatial? in: Capineri, C., Haklay, M., Huang, H., Antoniou, V., Kettunen, J., Ostermann, F., Purves, R. (Eds.), European Handbook of Crowdsourced Geographic Information, pp. 45-54. London: Ubiquity Press. DOI: https://doi.org/10.5334/bax.d

Campagna, M., 2014. The geographic turn in social media: Opportunities for spatial planning and Geodesign, in: Murgante, B., Misra, S., Rocha, A.M.A.C., Torre, C., Rocha, J.G., Falcão, M.I., Taniar, D., Apduhan, B.O., Gervasi, O. (Eds.), Computational Science and Its Applications - ICCSA 2014. Springer International Publishing, Cham, pp. 598-610. 
Campagna, M., Floris, R., Massa, P., Girsheva, A., Ivanov, K., 2015. The role of Social Media Geographic Information (SMGI) in spatial planning, in: Geertman, S., Ferreira, Jr, J.F., Goodspeed, R., Stillwell, J. (Eds.), Planning Support Systems and Smart Cities, Lecture Notes in Geoinformation and Cartography. Springer International Publishing, pp. 41-60.

Campagna, M., Mourão Moura, A.C., Borges, J., Cocco, C. 2016. Future scenarios for the Pampulha region: A Geodesign workshop, Journal of Digital Landscape Architecture 1, 292-301. DOI: https://doi. org/10.14627/537612033

Cerar, A., 2014. From reaction to initiative: Potentials of contributive participation. Urbani izziv 25, 93-106. DOI: https://doi.org/10.5379/urbani-izziven-2014-25-01-002

Cloke, P., May, J., Johnsen, S., 2008. Performativity and affect in the homeless city. Environment and Planning D: Society and Space 26, 241-263. DOI: https://doi.org/10.1068/d84j

Cloke, P., Milbourne, P., Widdowfield, R., 2003. The complex mobilities of homeless people in rural England. Geoforum 34, 21-35. DOI: https://doi. org/10.1016/S0016-7185(02)00041-6

Crystal, S., 1984. Homeless men and homeless women: The gender gap. Urban and Social Change Review 17, 2-6.

Dangermond, J., 2010. GeoDesign and GIS - Designing our Futures, in: Buhmann, E., Pietsch, X, Kretzler, X. (Ed.). Peer Reviewed Proceedings of Digital Landscape Architecture 2010. Anhalt University of Applied Sciences, Bernburg, Germany, pp. 502-514.

Davis, T.S., 2007. Mapping patterns of perceptions: A community-based approach to cultural competence assessment. Research on Social Work Practice 17, 358-379. DOI: https://doi.org/10.1177/1049731506295103

Elwood, S., Goodchild, M.F., Sui, D.Z., 2012. Researching volunteered geographic information: Spatial data, geographic research, and new social practice. Annals of the Association of American Geographers 102, 571-590. DOI: https://doi.org/10.1080/00045608.2011.595657

Envall, P., Koucky, M., 2013. Varför behöver man beskriva trafiknätets cykelvänlighet? En rapport inom CyCity. Cycity Bikeroute, Stockholm, Sweden.

Eräranta, S., Kahila-Tani, M., Nummi-Sund, P., 2015. Web-based public participation in urban planning competitions. International Journal of E-Planning Research 4, 1-18. DOI: https://doi.org/10.4018/ijepr.2015010101

Ervin, S., 2011. A system for GeoDesign, in: Proceedings of Digital Landscape Architecture. Anhalt University of Applied Science, pp. 145-154.

European Commission, 2003. Directive 2003-4-ES on providing for public participation in respect of the drawing up of certain plans and programmes relating to the environment. Brussels: Official Journal of EU 156-14.

Eurostat, 2012. Motorisation rate. Available at http://ec.europa.eu/eurostat/ web/products-datasets/-/tsdpc340 [Last accessed 9 May 2016]. 
Evans-Cowley, J., 2010. Planning in the real-time city: The future of mobile technology. Journal of Planning Literature 25, 136-149. DOI: https://doi. org/10.1177/0885412210394100

Fischer, F., 2000. Citizens, Experts, and the Environment: The Politics of Local Knowledge. Duke University Press, Durham, NC.

Frias-Martinez, V., Soto, V., Hohwald, H., Frias-Martinez, E., 2012. Characterizing urban landscapes using geolocated tweets, in: Proceedings of the 2012 ASE/IEEE International Conference on Social Computing and 2012 ASE/IEEE International Conference on Privacy, Security, Risk and Trust, SOCIALCOM-PASSAT'12. IEEE Computer Society, Washington, DC, USA, pp. 239-248. DOI: https://doi.org/10.1109/SocialCom-PASSAT.2012.19

Göçmen, Z.A., Ventura, S.J., 2010. Barriers to GIS use in planning. Journal of the American Planning Association 76, 172-183. DOI: https://doi. org/10.1080/01944360903585060

Goodchild, M.F., 2007. Citizens as sensors: the world of volunteered geography. GeoJournal 69, 211-221. DOI: https://doi.org/10.1007/s10708-007-9111-y

Gopsill, J.A., McAlpine, H.C., Hicks, B.J., 2013. A social media framework to support engineering design communication. Advanced Engineering Informatics 27, 580-597. DOI: https://doi.org/10.1016/j.aei.2013.07.002

Güler, K., 2015. Social media-based learning in the design studio: A comparative study. Computers \& Education 87, 192-203. DOI: https://doi. org/10.1016/j.compedu.2015.06.004

Harvey, D., 2008. The right to the city. New Left Review 53, 23-40.

Harvey, F., 2013. To volunteer or to contribute locational information? Towards truth in labeling for crowdsourced geographic information, in: Sui, D., Elwood, S., Goodchild, M. (Eds.), Crowdsourcing Geographic Knowledge. Springer Netherlands, Dordrecht, Netherlands, pp. 31-42.

Healey, C.G., Ramaswamy, S.S., 2016. Visualisation Twitter Sentiment. Available at https://www.csc.ncsu.edu/faculty/healey/tweet_viz/ [Last accessed 22 May 2016].

Human Cities, 2016. Fotozgodba naše soseske / Photo-story Our Neighbourhoods. Available at http://humancities.uirs.si/Domov.aspx [Last accessed 8 June 2016].

Jankowski, P., Andrienko, N., Andrienko, G., Kisilevich, S., 2010. Discovering landmark preferences and movement patterns from photo postings. Transactions in GIS 14, 833-852. DOI: https://doi.org/10.1111/j.14679671.2010.01235.x

Khakee, A., Barbanente, A., Borri, D., 2000. Expert and experiential knowledge in planning. The Journal of the Operational Research Society 51, 776. DOI: https://doi.org/10.2307/253959

Knoflacher, H., 2007. Success and failures in urban transport planning in Europe-understanding the transport system. Sadhana 32, 293-307. DOI: https://doi.org/10.1007/s12046-007-0026-6 
Latham, A., Wood, P.R.H., 2015. Inhabiting infrastructure: exploring the interactional spaces of urban cycling. Environment and Planning A 47, 300-319. DOI: https://doi.org/10.1068/a140049p

Lindblom, C.E., 1990. Inquiry and Change: The Troubled Attempt to Understand and Shape Society. Yale University Press, New Haven, Conn.

Longley, P.A., Adnan, M., Lansley, G., 2015. The geotemporal demographics of Twitter usage. Environment and Planning A 47, 465-484. DOI: https://doi. org/10.1068/a130122p

Lynch, K., 1960. The Image of the City. MIT Press, Cambridge, MA, USA.

Madanipour, A., Knierbein, S., Degros, A., 2014. A moment of transformation, in: Madanipour, A., Knierbein, S., Degros, A. (Eds.), Public Space and the Challenges of Urban Transformation in Europe. Routledge, London UK, pp. 1-8.

Massa, P., Campagna, M., 2014. Social Media Geographic Information: Recent findings and opportunities for smart spatial planning. TeMA Journal of Land Use, Mobility and Environment INPUT 2014 Special Issue, 645-658. DOI: https://doi.org/10.6092/1970-9870/2500

McTague, C., Jakubowski, S., 2013. Marching to the beat of a silent drum: Wasted consensus-building and failed neighborhood participatory planning. Applied Geography 44, 182-191. DOI: https://doi.org/10.1016/j. apgeog.2013.07.019

Nam, T., Pardo, T.A., 2011. Smart city as urban innovation: focusing on management, policy, and context, in: Proceedings of the 5th International Conference on Theory and Practice of Electronic Governance. ACM Press, pp. 185-194. DOI: https://doi.org/10.1145/2072069.2072100

Nonaka, I., Takeuchi, H., 1995. The Knowledge-creating Company: How Japanese Companies Create the Dynamics of Innovation. Oxford: Oxford University Press.

Noulas, A., Scellato, S., Mascolo, C., Pontil, M., 2011. Exploiting semantic annotations for clustering geographic areas and users in location-based social networks, in: Proceedings of the Social Mobile Web Workshop held during the 2011 ICWSM Conference, Barcelona, Spain, 21 July 2011, pp. $32-35$.

Nyerges, T., Ballal, H., Steinitz, C., Canfield, T., Roderick, M., Ritzman, J., Thanatemaneerat, W., 2016. Geodesign dynamics for sustainable urban watershed development. Sustainable Cities and Society 25, 13-24. DOI: https:// doi.org/10.1016/j.scs.2016.04.016

Pezzoni, N., 2011. The city and its vision. The collapse of urban representation: Migrants mapping Milan, in: My Ideal City. Scenarios for the European City of the 3rd Millennium. Università Iuav di Venezia, pp. 190-200.

Rantanen, H., Kahila, M., 2009. The SoftGIS approach to local knowledge. Journal of Environmental Management 90, 1981-1990. DOI: https://doi. org/10.1016/j.jenvman.2007.08.025 
Rivero, R., Smith, A., Balla, H., Steinitz, C., 2015. Promoting collaborative Geodesign in a multidisciplinary and multiscale environment: Coastal Georgia 2050, USA, in: Buhmann, E., Ervin, S., Pietsch, M. (Eds.), Proceedings of Digital Landscape Architecture 2015. Herbert Wichmann Verlag, Berlin, Germany, pp. 1-20.

Roche, S., Nabian, N., Kloeckl, K., Ratti, C., 2012. Are "Smart Cities" smart enough? Presented at the GSDI World Conference (GSDI 13), Global Spatial Data Infrastructure Association, Québec City, Canada, pp. 215-235.

Schaffers, H., Guzman, J.G., Navarro, M., Merz, C., 2010. Living Labs for Rural Development. Results from the C@ R Integrated Project, TRAGSA and FAO, Madrid, Spain.

Scholl, H.J., Nahon, K., Ahn, J.-H., Re, B., 2009. E-Commerce and E-Government: How do they compare? What can they learn from each other? Presented at the 42nd Hawaii International International Conference on Systems Science (HICSS-42 2009), IEEE, Waikoloa, Big Island, HI, USA, pp. 1-10. DOI: https://doi.org/10.1109/HICSS.2009.169

Seltzer, E., Mahmoudi, D., 2013. Citizen participation, open innovation, and crowdsourcing: Challenges and opportunities for planning. Journal of Planning Literature 28, 3-18. DOI: https://doi. org/10.1177/0885412212469112

Simon, H.A., 1969. The Sciences of the Artificial, 1st ed. MIT Press, Cambridge, Mass.

Steinitz, C., 2012. A Framework for Geodesign: Changing Geography by Design, 1st ed. Esri Press, Redlands, Calif.

Tominc, B., Bizjak, I., Mladenovič, L., Nikšič, M., 2012. CyCity Ljubljana. Cyclists' route choice and route preferences. Urban Planning Institute of the Republic of Slovenia, Ljubljana, Slovenia.

Torres, Y.Q.A., Costa, L.M.S.A., 2014. Digital narratives: Mapping contemporary use of urban open spaces through geo-social data. Procedia Environmental Sciences 22, 1-11. DOI: https://doi.org/10.1016/j. proenv.2014.11.001

Washburn, D., Sindhu, U., 2009. Helping CIOs Understand “Smart City” Initiatives, Making Leaders Successful Every Day. Forrester Research, Inc., Cambridge, MA, USA. Available at http://public.dhe.ibm.com/partnerworld/ pub/smb/smarterplanet/forr_help_cios_und_smart_city_initiatives.pdf [Last accessed 21 Mar 2014].

Winters, M., Teschke, K., Brauer, M., Fuller, D., 2016. Bike Score ${ }^{\varpi}$ : Associations between urban bikeability and cycling behavior in 24 cities. International Journal of Behavioral Nutrition and Physical Activity 13, 18. DOI: https:// doi.org/10.1186/s12966-016-0339-0

Wolch, J.R., Rahimian, A., Koegel, P., 1993. Daily and periodic mobility oatterns of the urban homeless. The Professional Geographer 45, 159-169. DOI: https://doi.org/10.1111/j.0033-0124.1993.00159.x 
Yeboah, G., Alvanides, S., 2015. Route choice analysis of urban cycling behaviors using OpenStreetMap: Evidence from a British urban environment, in: Jokar Arsanjani, J., Zipf, A., Mooney, P., Helbich, M. (Eds.), OpenStreetMap in GIScience. Springer International Publishing, Cham, pp. 189-210.

Zubelzu, S., Fernández, R.Á., 2016. Carbon Footprint and Urban Planning: Incorporating Methodologies to Assess the Influence of the Urban Master Plan on the Carbon Footprint of the City. Springer. 
